\title{
A design and implementation of low-power ultrasonic water meter
}

\author{
Youn-Sik Hong ${ }^{*}$ and Chul-Ho Lee
}

\author{
* Correspondence: yshong@inu.ac.kr \\ Department of Computer Science \\ and Engineering, Incheon National \\ University, Incheon 22012, Korea
}

\begin{abstract}
Smart water meter, which incorporates loT (Internet of Things) technology, is receiving high attention due to recent development of information and communication technology. If traditional mechanical water meters are replaced by electronic ultrasonic water meters, micro flow rate can be measured and the measurement uncertainty can be improved due to the age of use. This enables smart metering such as AMR (Automatic Meter Reading) or AMI (Advanced Metering Infrastructure) as well as various water related services. In this paper, a low power ultrasonic water meter will be designed to operate with a battery for a long period of time. A water meter shall be designed to operate for at least 9 years, which is the requirement for type approval. In this paper, a low-power modeling is performed for battery-operated ultrasonic water meter to work for at least 10 years. The proposed low power embedded system model will be verified with actual test circuits.
\end{abstract}

Keywords: Smart water meter, dToF, Coefficient of time (CT), Ultrasonic water meter

\section{Introduction}

The operating period required by the type approval of a water meter shall be 8 years. However, a water meter shall be designed to operate for at least 9 years, since it would be operated for additional 1 year during the replacement period. In this paper, a lowpower modeling is performed for battery-operated ultrasonic water meter to work for at least 10 years (Ministry of Industry and Commerce, 2015).

The technical criteria for the lifetime of electronic devices in water meter are clearly stated in the type approval standard. However, the method for evaluating their lifetime has not yet been described in the technical standards. In particular, if a battery (including primary and secondary batteries) is used, it is difficult to evaluate whether it can be used without battery discharge during the type approval period (8 years).

Traditional ultrasonic flow meters need devices for processing ultrasonic signals. However, with the development of the front-end chip for calculating ultrasonic propagation time (called time-of-flight (ToF)) (Maxim Integrated Products Inc., 2015; Texas Instruments, 2015), ultrasonic water meters that operate at low power have become possible. Furthermore, as high-performance microcontrollers (MCUs) that operate at low power have been developed, the possibility of high-performance ultrasonic water meters at low power has increased.

This paper deals with the electrical characteristics of a microcontroller (MCU) and a front-end chip for low power modeling of an ultrasonic water meter and low power

(c) The Author(s). 2019 Open Access This article is distributed under the terms of the Creative Commons Attribution 4.0 International License (http://creativecommons.org/licenses/by/4.0/), which permits unrestricted use, distribution, and reproduction in any medium, provided you give appropriate credit to the original author(s) and the source, provide a link to the Creative Commons license, and indicate if changes were made. 
algorithm of embedded software to control the MCU. As shown in Fig. 1, the ultrasonic water meter proposed in this paper consists of a low-power microcontroller including a LCD device, an ultrasonic front-end chip including two ultrasonic transducers, and a power circuit including a battery. On the other hand, the external communication unit is not covered in this paper because it is operated in accordance with the meter-bus (M-BUS) standard and operates on separate batteries.

We have designed and implemented a small diameter ultrasonic water meter. Then we propose a low power design for such battery-powered smart meter to be operated for the next 8 years and verify our proposed design by an actual model.

The remainder of this paper is organized as follows. We describe design of low power ultrasonic water meter in Section 2. Section 3 shows the test results to validate the proposed method. Finally, conclusions are drawn in Section 4.

\section{Design of low power ultrasonic water meter}

\section{Design of the dToF type ultrasonic water meter}

We have already designed and implemented the dToF type ultrasonic water meter in our previous research (Lee et al., 2017), and here is a brief overview. Figure 2 shows the structure of the flow measurement unit with the ultrasonic wave transmission time difference (Lee C-H, Hong Y-S (2014), Lee \& Hong, 2015; Spitzer, 1990; Flowmeter classification and features, 2015; Lee \& Hong, 2016). It can measure the flow rate of a small diameter pipe such as a water meter in home. This structure is suitable for measuring the flow rate of a small diameter and is mainly used in industrial applications. Ultrasonic transducers are attached to the upstream pipe (Sensor1) and downstream pipe (Sensor2) as shown in the Fig. 2.

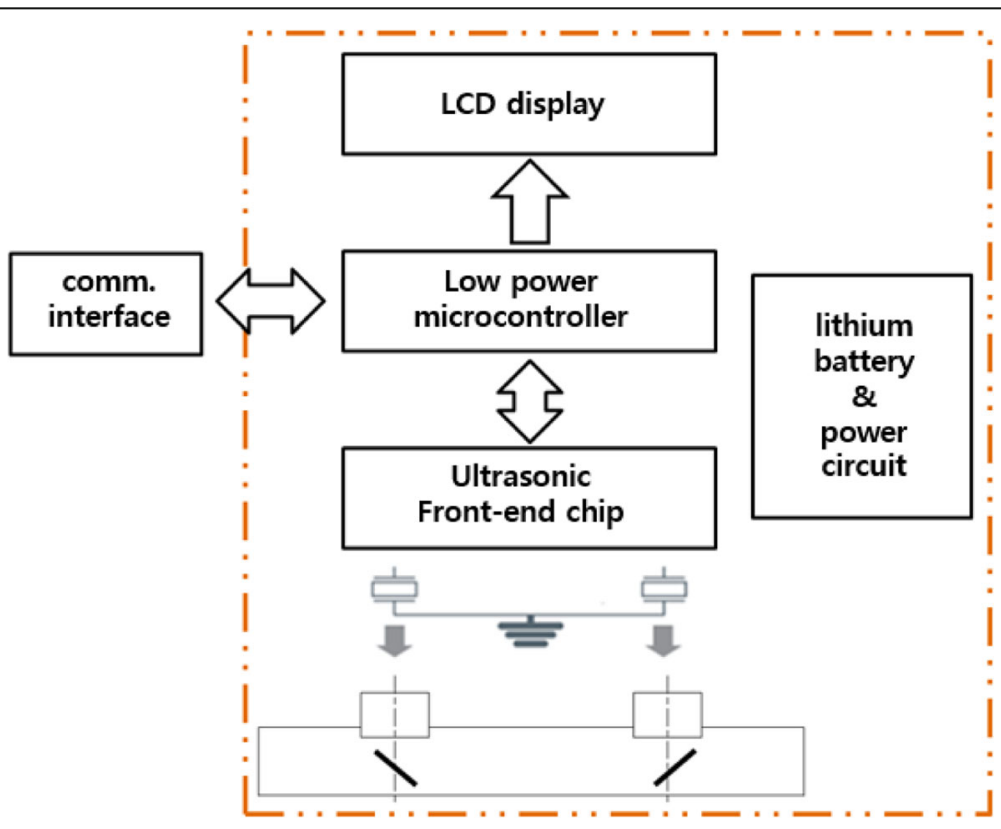

Fig. 1 The operation flow of the dToF-type water meter 


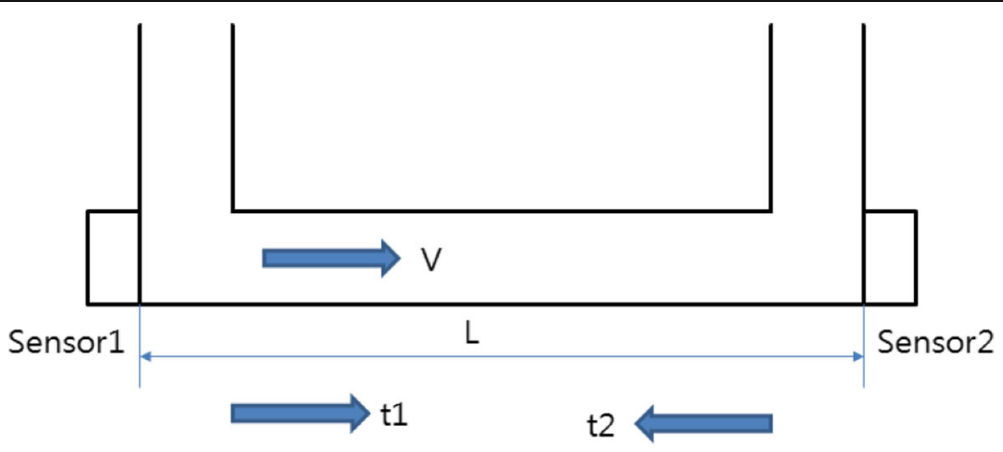

Fig. 2 Small-diameter ultrasound transmission time-difference flow measurement concepts

By accurately measuring the upstream and downstream transit-time $t_{1}$ and $t_{2}$, and $\Delta t=t_{2}-t_{1}$, The flow velocity $V$ and the flow rate $Q$ can be calculated as following (Lee et al., 2017):

$$
\begin{aligned}
& V=\frac{L \Delta t}{2 t_{0}^{2}} \\
& Q=\frac{\pi}{4} d^{2} \frac{L \Delta t}{t 1+t 2}
\end{aligned}
$$

From Eq.1 and Eq.2, we see that the measurement results, $V$ and $Q$, are independent of fluid properties, pressure, temperature, pipe materials, etc. The method of obtaining the flow rate using Eq.2 is called differential time of flight (dToF) method in order to distinguish it from the ultrasonic wave transit time difference method (Lee et al., 2017).

The structure of the dToF-type ultrasonic flow measurement used in this paper is shown in Fig. 3. Both a pair of ultrasonic transducers and a pair of ultrasonic reflectors are installed on the upstream and downstream of the pipeline through which water flows. Notice that the ultrasonic transducers are designed to be less susceptible to fluid flow.

In Fig. 3, the ultrasonic waves emitted from the upper side transducer are reflected at $45^{\circ}$ from the upstream reflector and transmitted in the flow direction. The ultrasonic signal of the upper side transducer in the flow direction is reflected at the downstream reflector to be transmitted to the lower side transducer. This downstream ultrasonic wave is transmitted in the flow direction and reaches the lower side transducer after

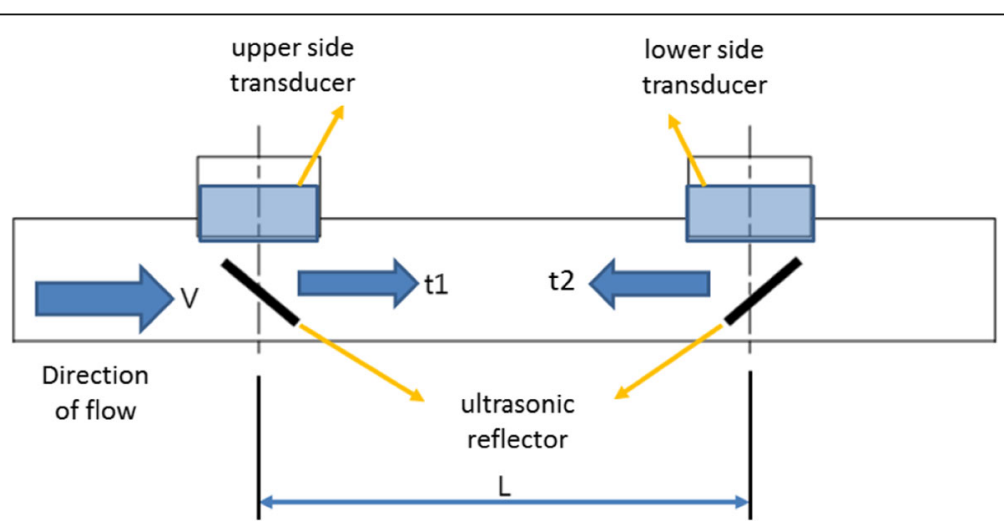

Fig. 3 the structure of a dToF-type ultrasonic flow measurement 
the time $t_{1}$ elapses. In contrast, the upstream ultrasonic waves are transmitted in the opposite direction of flow and reach the upper side transducer after the time $t_{2}$ elapses.

The measurement error was measured for the four zones of flow rates. Figure 4 shows the comparison of the measurement errors between the proposed dToF-type ultrasonic water meter and the existing water meter. In Fig. 4(a), 13A to 13I, 20A to $20 \mathrm{~F}$ and $25 \mathrm{~A}$ to $25 \mathrm{D}$ refer to the measurement errors of the existing mechanical water meters of DN15 $(13 \mathrm{~mm}), \mathrm{DN} 20(20 \mathrm{~mm})$ and DN25 $(25 \mathrm{~mm})$ respectively. On the other hand, $1 \mathrm{~A}$ to $1 \mathrm{C}, 2 \mathrm{~A}$ to $2 \mathrm{C}$, and $3 \mathrm{~A}$ to $3 \mathrm{C}$ are the measurement errors for the dToF-type meter. Figure 4(b) shows only the results of the dToF-type meters for more clear distinction. As can be seen in Fig. 4, it can be seen that the error of the existing water meter reaches up to $40 \%$ in the low flow rate zone Q1.

\section{Power consumption design modeling}

In the power consumption modelling, a power $P$ is proportional to current $I$ and voltage $E$.

$$
P=E \times I
$$

An electric energy $W$ is the power $P$ multiplied by the operating time $t$. Then it can be expressed as the product of voltage $V$, current $I$, and time $t$.

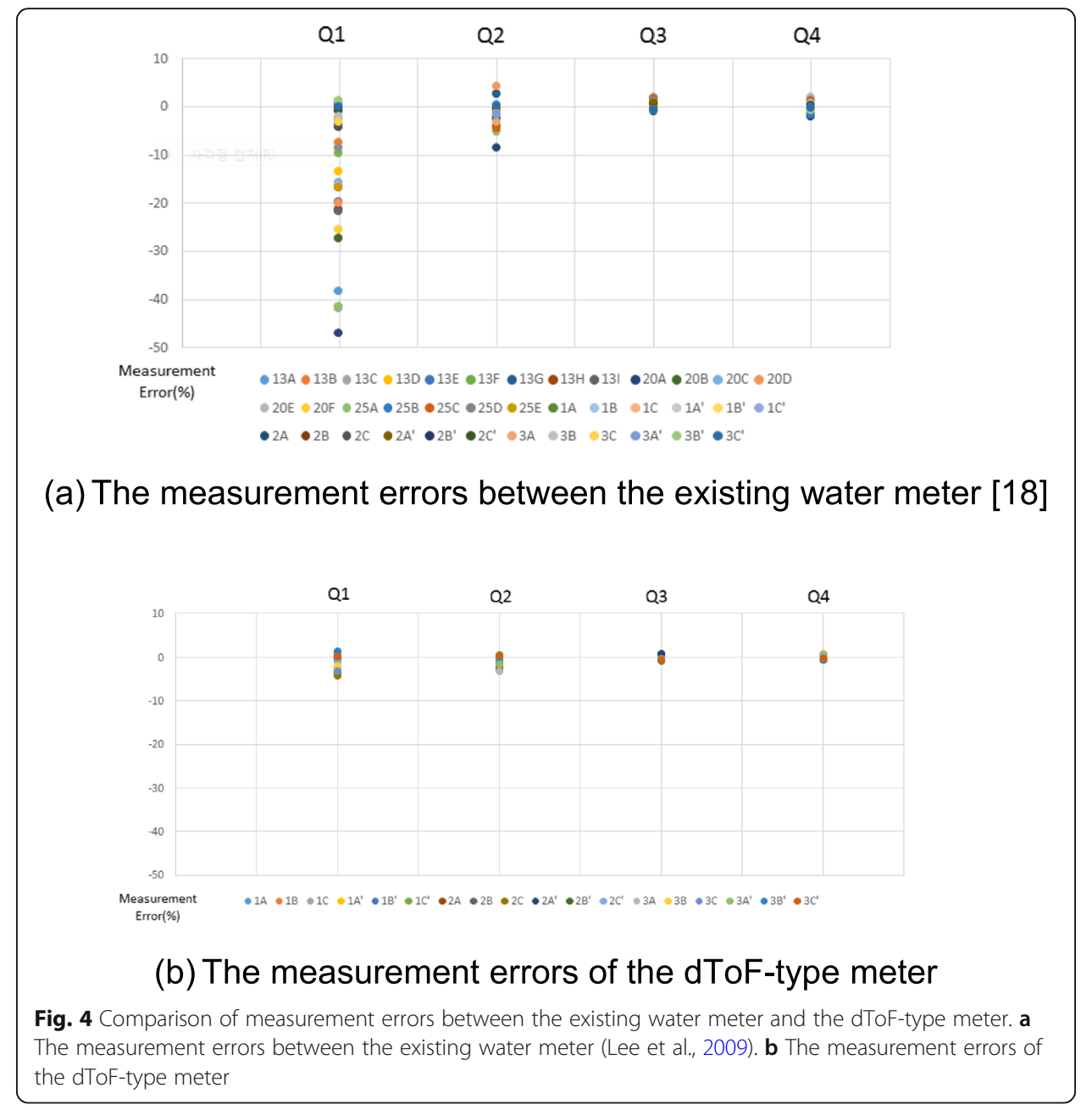




$$
W=P \times t=E \times I \times t
$$

The unit of electric power $W$ is $J, W s$, and $W h$. We use $[W h]$ as the unit of the $W$, which indicates how much time the power was used. Notice that the $[W h]$ is a unit of energy equivalent to unit power (1 watt) expended for unit time $(1 \mathrm{~h})$.

In the case of battery, the voltage $E$ is fixed, so we do not use the equation $E \times I \times t$, but use $I \times t$, in which $E$ is omitted. The unit is also expressed by either $[A h]$ or $[m A h]$. Similarly, the amount of power consumed by the battery-operated ultrasonic water meter is measured in either $[A h]$ or $[m A h]$. In order to model the power consumption of the ultrasonic water meter, the notations for voltage and current consumption are listed in Table 1 for the microcontroller (MCU, STM32L162) and the front-end chip (FE, MAX35101), respectively.

Notice that $P_{\text {active }}$ and $P_{\text {idle }}$ represents power consumption active state and idle state, respectively. In addition, $P_{\text {total }}$ is the total sum of power consumption, $P_{\text {total }}=P_{\text {active }}+P_{\text {idle }}$. In a similar way, $W_{\text {active }}$ and $W_{\text {idle }}$ represents energy at active state and idle state, respectively. In addition, $W_{\text {total }}$ is the total sum of energy, $W_{\text {total }}=W_{\text {active }}+W_{\text {idle }}$

$$
\begin{aligned}
& P_{\text {total }}=P_{\text {active }}+P_{\text {idle }} \\
& P_{\text {active }}=\left(I_{\text {active }}^{M C U} \times E_{\text {active }}^{M C U}\right)+\left(I_{\text {active }}^{F E} \times E_{\text {active }}^{F E}\right) \\
& P_{\text {idle }}=\left(I_{\text {idle }}^{M C U} \times E_{\text {idle }}^{M C U}\right)+\left(I_{\text {idle }}^{F E} \times E_{\text {idle }}^{F E}\right) \\
& W_{\text {total }}=W_{\text {active }}+W_{\text {idle }} \\
& W_{\text {active }}=\left(I_{\text {active }}^{M C U} \times E_{\text {active }}^{M C U}\right) \times T_{\text {active }}^{M C U}+\left(I_{\text {active }}^{F E} \times E_{\text {active }}^{F E}\right) \times T_{\text {active }}^{F E} \\
& W_{\text {idle }}=\left(I_{\text {idle }}^{M C U} \times E_{\text {idle }}^{M C U}\right) \times T_{\text {idle }}^{M C U}+\left(I_{\text {idle }}^{F E} \times E_{\text {idle }}^{F E}\right) \times T_{\text {idle }}^{F E}
\end{aligned}
$$

The energy consumption at the active $W_{\text {active }}$ and the power consumption at idle state $W_{\text {idle }}$ are used to model the total power consumption $W_{\text {total }}$. This model can be used to determine the maximum amount of energy consumed by the entire system. Based on this value, the model to be proposed is intended to reduce current consumption.

On the other hand, using the power consumption, it can calculate the elapsed time of battery usage of the ultrasonic water meter. Since the ultrasonic water meter proposed

Table 1 The notations used in power consumption model

\begin{tabular}{ll}
\hline notation & Description \\
\hline$E_{M C U}$ & Supply voltage of the STM32L162 microcontroller (MCU) \\
$E_{F E}$ & Supply voltage of the MAX35101 front-end chip (FE) \\
$I_{a c t i v e}^{M C U}$ & Current consumption of the MCU in the run mode (active state) \\
$I_{a c t i v e}^{F E}$ & Current consumption of the FE in the active state \\
$I_{\text {idle }}^{M C U}$ & Current consumption of the MCU in the idle mode (idle state) \\
$I_{\text {idde }}^{F E}$ & Current consumption of the FE in the idle state \\
$T_{a c t i v e}^{M C U}$ & Operating time of the MCU in the active state \\
$T_{\text {idle }}^{M C U}$ & Operating time of the MCU in the idle state \\
$T_{a c t i v e}^{F E}$ & Operating time of the ToF in the active state \\
$T_{\text {idle }}^{F E}$ & Operating time of the FE in the idle state \\
\hline
\end{tabular}


in this paper uses battery as a power source, the energy $W$ is measured as a unit of [ $m A h]$ excluding the voltage $E$ as explained earlier. Thus, the above equations can be rewritten as follows:

$$
\begin{aligned}
& P_{\text {total }}=P_{\text {active }}+P_{\text {idle }} \\
& P_{\text {active }}=I_{\text {active }}^{M C U}+I_{\text {active }}^{F E} \\
& P_{\text {idle }}=I_{\text {idle }}^{M C U}+I_{\text {idle }}^{F E} \\
& W_{\text {total }}=W_{\text {active }}+W_{\text {idle }} \\
& W_{\text {active }}=I_{\text {active }}^{M C U} \times T_{\text {active }}^{M C U}+I_{\text {active }}^{F E} \times T_{\text {active }}^{F E}<P_{\text {active }} \times T_{\text {active }} \\
& (\text { Where, }), T_{\text {active }}=\max \left(T_{\text {active }}^{M C U}, T_{\text {active }}^{F E}\right) \\
& W_{\text {idle }}=I_{\text {idle }}^{M C U} \times T_{\text {idle }}^{M C U}+I_{\text {idle }}^{F E} \times T_{\text {idle }}^{F E}<P_{\text {idle }} \times T_{\text {idle }} \\
& (\text { where, }), T_{\text {idle }}=\max \left(T_{\text {idle }}^{M C U}, T_{\text {idle }}^{F E}\right) \\
& W=P_{\text {total }} \times T_{\text {total }},
\end{aligned}
$$

where,

$$
\begin{aligned}
& T_{\text {total }}=T_{\text {active }}+T_{\text {idle }} \\
& T_{\text {hour }}=B_{\text {capacity }} / P_{\text {total }}
\end{aligned}
$$

Where, $B_{\text {capacity }}$ and $T_{\text {hour }}$ represents the battery power (unit: $m A h$ ) and the battery usage time, respectively.

\section{Analysis of the major components of the ultrasonic water meter}

We analyze power consumption through low power design modeling of the proposed ultrasonic water meter. Through this, it is designed to be able to operate only with the battery during the demand period according to the technical standard of water meters. The major components involved in the power consumption of the ultrasonic water meter are the microcontroller including LCD device and the front-end chip including ultrasonic transducer as described above. We review electrical specifications for these two parts.

The microcontroller STM32L162 used in this paper is equipped with 2-bit ARM Cortex $\mathrm{M} 3$, and operates at voltage range $1.65 \mathrm{~V}$ to $3.6 \mathrm{~V}$. It supports standby mode, stop mode, low-power run mode, and run mode. It consumes $8.6 \mu \mathrm{A}$ of current at lowpower operating conditions and $19 \mu \mathrm{A}$ at high temperature such as $85^{\circ} \mathrm{C}$. It also contains the LCD device and DMA (Direct Memory Access) controllers. In the stop mode, the LCD device can be operated in addition to the RTC (Real Time Clock) operation, in which the power consumption is less than $10 \mu A$ at room temperature.

In the run mode (or normal operation), $400 \mu A$ current is consumed even with minimum power, and up to $4 \mathrm{~mA}$ is consumed when operated at $16 \mathrm{MHz}$, making it impossible to use the battery for 10 years. To simplify the modeling, it is assumed that the microcontroller operates in two modes: the low power run mode and the stop mode with the RTC switched on.

The current consumption to drive the LCD device consumes $4 \mu A$ at the low power run mode or the stop mode. The current consumption associated with the watch-dog is known as $3 \mu \mathrm{A}$. When the ultrasonic water meter turns off the LCD device during 
normal operation, about $4 \mu \mathrm{A}$ of current consumption can be saved. However, when implementing an actual ultrasonic water meter, buttons or optical sensors should be used to perform the functions of turning the LCD device on and off. In this process, the current consumed to operate the sensors required must be considered. Therefore, it should be judged based on the result of the final low-power design modeling whether it is better to save $4 \mu A$ by switching the LCD device on and off, or whether it should always be turned on. Notice that it is only reviewed from the perspective of the amount of power consumed, without considering the lifetime of the LCD device.

The hardware that is important to design and implement the $\mathrm{dToF}$ (differential time of flight) type ultrasonic water meter is the front-end chip that calculates the propagation time of ultrasonic (i.e., $T o F$ ). In this paper, we use the low-power ToF measurable front-end chip from Maxim (Maxim Integrated Products Inc., 2015), one of the US semiconductor companies.

\section{Modeling of power consumption of the ultrasonic water meter}

We want to design a low power consumption model so that the ultrasonic water meter can measure the flow rate of tap water for 10 years which is a requirement of the legal meter. Table 2 shows the current consumption and the power consumption of the microcontroller and the front-end chip mentioned in Section 2.3.

For low-power modeling, the power consumption is calculated using the typical value of the current consumption. In case of several typical values, it is set as the one when the ambient temperature is $85^{\circ} \mathrm{C}$.

The operating time of the proposed ultrasonic water meter is designed by the front-end chip transmitting the ToF data to the MCU once every $2 \mathrm{~s}$. The front-end chip operates in the run mode for $2.5 \mathrm{~ms}$ of the $500 \mathrm{~ms}$ cycle. It processes ultrasonic signals using the ultrasonic transducer and calculates ToF twice per second. The MCU is designed to operate four times every two seconds. These relationships are shown in Fig. 5. Based on this, we calculate the active time and idle time of the MCU and the FE chip.

$$
\begin{aligned}
& T_{\text {active }}^{M C U}=2.5 \mathrm{~ms} \\
& T_{\text {idle }}^{M C U}=2000 \mathrm{~ms} 2.5 \mathrm{~ms}=1997.5 \mathrm{~ms} \\
& T_{\text {active }}^{F E}=2.5 \mathrm{~ms} \times 4=10 \mathrm{~ms} \\
& T_{\text {idle }}^{F E}=500 \mathrm{~ms} \times 4-10 \mathrm{~ms}=1990 \mathrm{~ms}
\end{aligned}
$$

\begin{tabular}{|c|c|c|c|c|c|}
\hline device & $\begin{array}{l}\text { operating } \\
\text { status }\end{array}$ & $\begin{array}{l}\text { operating } \\
\text { condition }\end{array}$ & $\begin{array}{l}\text { Supply Voltage } \\
\text { [V] }\end{array}$ & $\begin{array}{l}\text { current } \\
\text { consump. }[\mu A]\end{array}$ & $\begin{array}{l}\text { power consump. } \\
{[\mu \mathrm{W}]}\end{array}$ \\
\hline \multirow{4}{*}{$\begin{array}{l}\text { STM32L152 } \\
\text { Micro } \\
\text { controller }\end{array}$} & \multirow[t]{2}{*}{ active } & typical & \multirow[t]{4}{*}{3.6} & 19.0 & 68.4 \\
\hline & & $\max$ & & 47.0 & 169.2 \\
\hline & \multirow[t]{2}{*}{ idle } & typical & & 6.25 & 22.5 \\
\hline & & $\max$ & & 44.0 & 158.4 \\
\hline \multirow{4}{*}{$\begin{array}{l}\text { MAX35101 Front-end } \\
\text { chip }\end{array}$} & \multirow[t]{2}{*}{ active } & typical & & 10.0 & 36.0 \\
\hline & & $\max$ & & 13.0 & 46.8 \\
\hline & \multirow[t]{2}{*}{ idle } & typical & & 0.1 & 0.36 \\
\hline & & $\max$ & & 1.0 & 3.6 \\
\hline
\end{tabular}

Table 2 Current consumption of each device at the run mode 


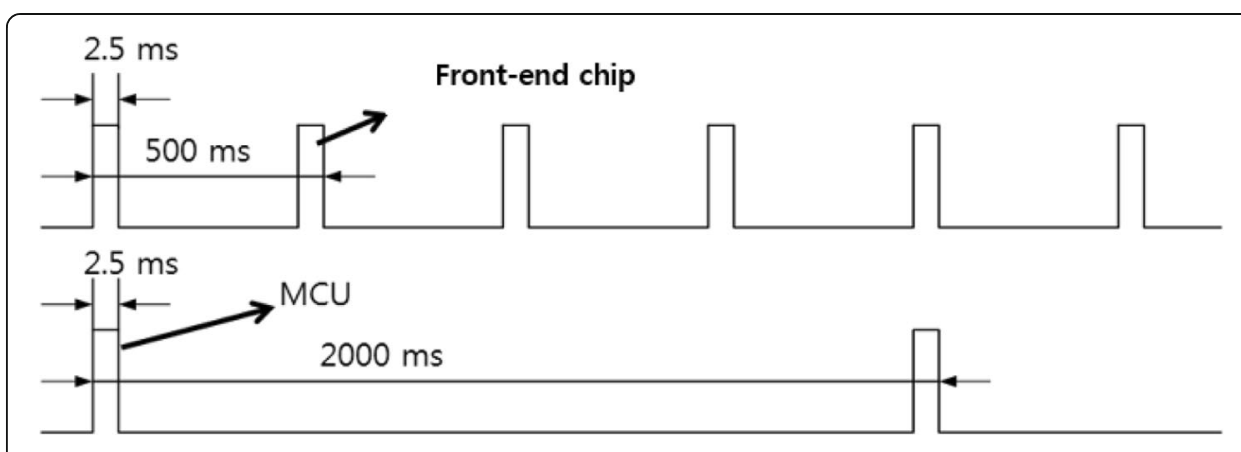

Fig. 5 Timing diagram of the proposed low power model

The MCU runs once for every $2 \mathrm{~s}$ and the front-end chip runs four times for every 2 s. Therefore, based on $2 \mathrm{~s}$, we need to figure out how much current is consumed. The current consumption can be obtained more effectively by using a coefficient of time (CT). That is, when the front-end chip is active, the model can be simplified by adding all the power consumption at each active time slot. The simplified timing diagram using CT is shown in Fig. 6.

$$
\begin{aligned}
& T_{\text {total }}=T_{\text {active }}+T_{\text {idle }} \\
& C T_{\text {active }}^{M C U}=T_{\text {active }}^{M C U} / T_{\text {total }}=2.5 / 2000=0.00125 \\
& C T_{\text {active }}^{F E}=T_{\text {active }}^{F E} / T_{\text {total }}=10 / 2000=0.005 \\
& C T_{\text {idle }}^{M C U}=\left(T_{\text {total }}-T_{\text {active }}^{M C U}\right) / T_{\text {total }}=0.99875 \\
& C T_{\text {idle }}^{F E}=\left(T_{\text {total }}-T_{\text {active }}^{F E}\right) / T_{\text {total }}=0.995
\end{aligned}
$$

Notice that $C \boldsymbol{T}_{\text {active }}^{M C U}$ and $\boldsymbol{C} \boldsymbol{T}_{\text {active }}^{F E}$ represents the CT of the MCU and the CT of the FE in the active state, respectively. Besides, $C T_{\text {idle }}^{M C U}$ and $C T_{\text {idle }}^{F E}$ represents the CT of the MCU and the CT of the FE in the idle state, respectively.

As shown in Table 2, the MCU consumes $19 \mu A$ (up to $47 \mu A$ ) in the active state (2.5 $m s$ ) and $6.25 \mu A$ (up to $44 \mu A$ ) in the idle state (1997.5 ms). When the current consumption of the MCU and the FE is the typical value, the power consumption can be calculated using Eq.5, Eq.6 and Eq.7'as follows.

$$
P_{\text {active }, \text { typical }}=19 \mu \mathrm{A} \times 0.001245+10 \mu \mathrm{A} \times 0.005=0.07375 \mu \mathrm{A}
$$

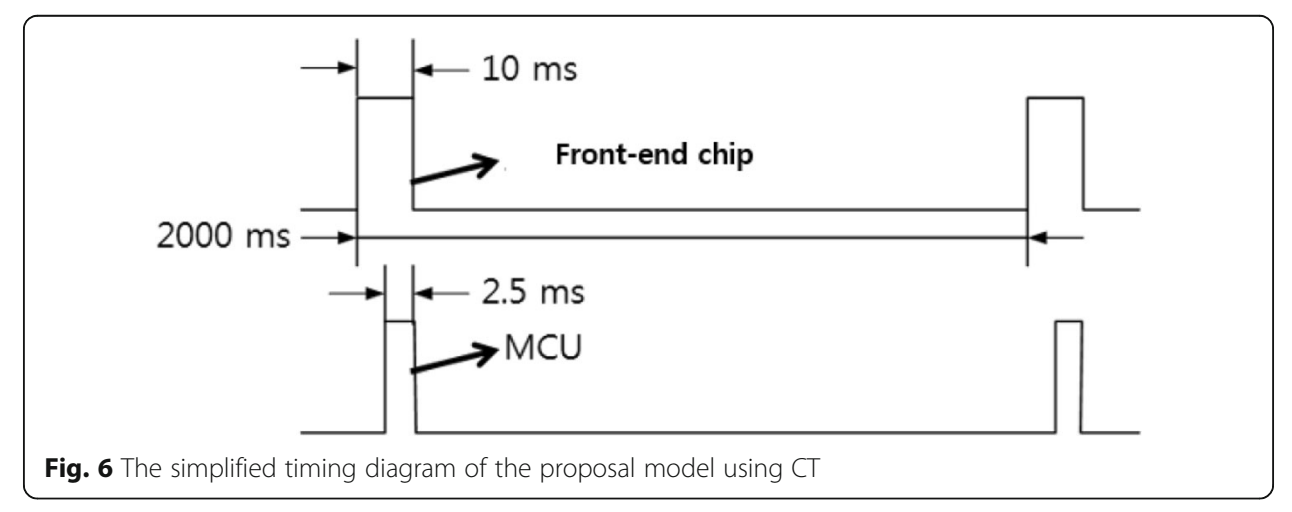




$$
\begin{aligned}
& P_{\text {idle,typical }}=6.25 \mu \mathrm{A} \times 0.99875+0.1 \mu \mathrm{A} \times 0.995=6.34169 \mu \mathrm{A} \\
& P_{\text {total,typical }}=0.07375 \mu \mathrm{A}+6.34169 \mu \mathrm{A}=6.41544 \mu \mathrm{A}
\end{aligned}
$$

When the current consumption of the $\mathrm{MCU}$ and the $\mathrm{FE}$ is the maximum value, the power consumption is calculated as follows.

$$
\begin{aligned}
& P_{\text {active, } \max }=47 \mu \mathrm{A} \times 0.001245+13 \mu \mathrm{A} \times 0.005=0.1238 \mu \mathrm{A} \\
& P_{\text {idle, } \text { max }}=44 \mu \mathrm{A} \times 0.99875+1 \mu \mathrm{A} \times 0.995=44.94 \mu \mathrm{A} \\
& P_{\text {total } \text { max }}=0.1238 \mu \mathrm{A}+44.94 \mu \mathrm{A}=45.0638 \mu \mathrm{A}
\end{aligned}
$$

Using the Eq.13, the battery capacity for 10 years can be obtained as follows:

$$
\begin{aligned}
& B_{\text {capacity }}^{\text {max }}=(24 \times 365 \times 10) \times 45.0638 \mu A=3,947 \mathrm{mAh} \\
& B_{\text {capacity }}^{\text {typical }}=(24 \times 365 \times 10) \times 6.41544 \mu \mathrm{A}=562 \mathrm{mAh} \\
& B_{\text {capacity }}^{\text {geomean }}==\sqrt{B_{\text {capacity }}^{\text {max }} \times B_{\text {capacity }}^{\text {typical }}}=\sqrt{3,947 \times 562}=1,489 \mathrm{mAh}
\end{aligned}
$$

Notice that the maximum power consumption is $3947 \mathrm{mAh}$ and the typical power consumption is $562 \mathrm{mAh}$. In addition, the geometric mean and the arithmetic mean of these two values are $1489 m A h$ and $2254 m A$, respectively. The power consumption calculated here is just an estimate, not a statistics of the measured values. Thus it is appropriate to use a geometric mean rather than an arithmetic mean.

Generally, the safety factor (sf) for calculating the battery capacity is set to 0.8 (or 80\%) (ACAM Messelektromik gmbh, 2015) and 1.2(or 120\%) (http://www.powerstream.com/battery-capacity-calculations.htm, 2015), but in this paper it is set to 2.0 (or $200 \%)$ to fully satisfy the requirement of the legal meter. Using this value, we calculate the maximum capacity of the battery as follows.

$$
B_{\text {capacity }}^{s f=2.0}=B_{\text {capacity }}^{\text {max }} \times 2.0=7,900 \mathrm{mAh}
$$

Cylindrical shaped batteries, including lithium batteries, are available in D, C, A, AA, AAA types from the largest DD size. Lithium batteries generally use 2/3 AA type, 1/2 AA type, which is shorter than AA type, rather than AAA type. Referring to the lithium battery specification in Table 3, a lithium battery with a capacity of $8500 \mathrm{mAh}$ is chosen. The life span of the ultrasonic water meter for the maximum power consumption reflecting the $200 \%$ safety index in Eq. 31 is as follows.

$$
T_{\text {hour }}=\frac{8500 m A h \times 1000}{45.0638 \mu A} \times 0.5=94,310[\text { hours }]=10.7[\text { years }]
$$

The ultrasonic water meter proposed in this paper can be used for up to 10 years in the maximum power consumption model, even taking into account of the safety factor of 2.0 using a lithium battery of $8500 \mathrm{mAh}$.

\section{System implementation and performance evaluation Implementation of the dToF-type water meter}

The stm32L162 with a low-power Cortex-M3 is used for the MCU. As explained earlier, the MAX35101 chip is used to measure ToF in the both directions. Fig. 7a shows 
Table 3 Lithium battery specifications for water meters (http://www.evebattery.com/en2/ products.aspx?category $=40,2015$ )

\begin{tabular}{|c|c|c|c|c|c|c|}
\hline \multirow[t]{2}{*}{ Model } & \multirow[t]{2}{*}{ Size } & \multirow{2}{*}{$\begin{array}{l}\text { Capacity } \\
(m A h)\end{array}$} & \multirow{2}{*}{$\begin{array}{l}\text { Max } \\
\text { continuous } \\
\text { discharge } \\
\text { current }(m A)\end{array}$} & \multicolumn{2}{|l|}{ Size } & \multirow{2}{*}{$\begin{array}{l}\text { Weight } \\
(\mathrm{g})\end{array}$} \\
\hline & & & & Diameter $(\mathrm{mm})$ & $\mathrm{H} / \mathrm{D}(\mathrm{mm})$ & \\
\hline ER14250 & $1 / 2 \mathrm{AA}$ & 1200 & 15 & 14.5 & 25.4 & 10 \\
\hline ER14335 & $2 / 3 \mathrm{AA}$ & 1650 & 75 & 14.5 & 33.5 & 12 \\
\hline ER14505 & AA & 2700 & 40 & 14.5 & 50.5 & 19 \\
\hline ER17505 & A & 3600 & 130 & 17.5 & 50.5 & 26 \\
\hline ER18505 & A & 4000 & 130 & 18.7 & 50.5 & 28 \\
\hline ER26500 & C & 8500 & 150 & 26.2 & 50.0 & 52 \\
\hline ER34615 & D & 19000 & 230 & 33.1 & 61.5 & 100 \\
\hline ER341245 & $\mathrm{DD}$ & 35000 & 420 & 33.1 & 124.5 & 195 \\
\hline
\end{tabular}

the dToF-type ultrasonic water meter of $15 \mathrm{~mm}$ diameter with two ultrasonic transducers. The dimensions of the dToF-type water meter are given in Fig. 7b. Figure 7c shows the manufactured dToF-type water meter.

\section{Low power test and evaluation}

In order to verify the low power design of the ultrasonic water meter proposed in this paper, the current consumption was measured as shown in Fig. 8. With the ultrasonic water meter connected to the batteries, current consumption was measured by connecting a digital multi-meter that could be measured in $0.01 \mu \mathrm{A}$ units.

At initial, we tried to measure power consumption while the ultrasonic water meter was operating as shown in Fig. 4. However, the current consumed by the MCU changed too quickly, so that only the average of the current consumption could be measured. Therefore, the current consumption was measured while the MCU was operating in the low power run mode. The current consumption was then measured by operating the MCU as an idle state. These measures of the current consumption are used to obtain power consumption, and the results are summarized in Table 4.

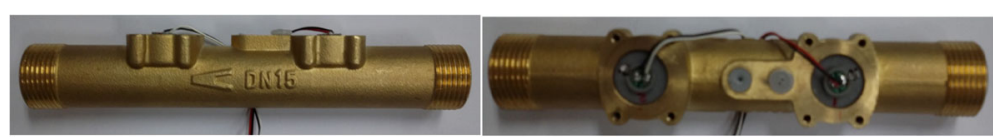

$\begin{array}{ll}\text { (a) The side section } & \text { (b) The upper section }\end{array}$

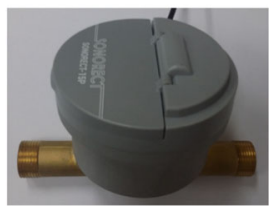

(c) The manufactured ultrasonic water meter.

Fig. 7 The dToF-type ultrasonic water meter. a The side section. b The upper section. c The manufactured ultrasonic water meter 


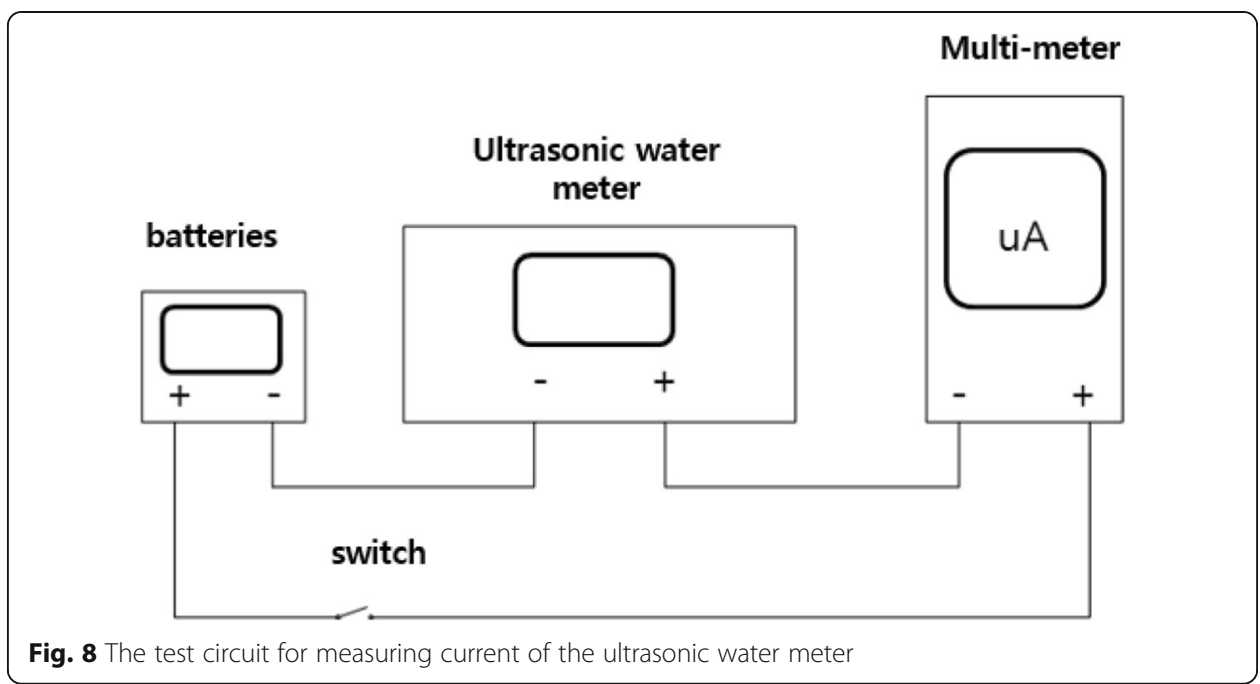

Table 5 summarizes the power consumption using the current consumption in Table 4, the power consumption when used for 10 years, and the life span in years when using an $8500 m A h$ battery. The average consumption current of $20.92 \mu A$ in Table 5 is smaller than the value obtained by the power consumption modeling $(45.06 \mu A)$. On the other hand, it is somewhat larger than the geometric average of $17.0 \mu \mathrm{A}$ predicted by the power consumption modeling. That is, the actual current consumption is close to the typical value rather than the maximum current consumption of the data sheet.

For power consumption, it was expected that the $8500 \mathrm{mAh}$ battery would be available for more than 20 years. Compared to the geometric mean (1489.9 $\mathrm{mAh})$ obtained from the power consumption modeling, the actual measurement indicates that the measured geometric mean (1830.5 $m A h)$ is meaningful.

\section{Conclusion}

In this paper, the $\mathrm{dToF}$ flow measurement method has been applied to water meters. It has been also implemented to operate at low power for 10 years, exceeding the type approval period of a water meter. The actual measurement of the current consumption using the $8500 m A h$ battery has proved that the proposed low power modeling works well.

The low power ultrasonic water meter implemented in this paper is expected to be able to operate for more than 10 years in various environments including external wired/wireless communication, installation of temperature sensor, integration with advanced networks such as IoT (Internet of Things) including smart metering.

Smart meters such as our proposed ultrasonic water meters can operate with external power when using M-bus. Therefore, it would be desirable to design optical coupling

Table 4 The measured current consumption using the test circuit

\begin{tabular}{llll}
\hline mode & 1st measurement & 2nd measurement & 3rd measurement \\
\hline Active mode & $41.21 \mu \mathrm{A}$ & $39.36 \mu \mathrm{A}$ & $39.74 \mu \mathrm{A}$ \\
ldle mode & $21.87 \mu \mathrm{A}$ & $20.23 \mu \mathrm{A}$ & $20.29 \mu \mathrm{A}$ \\
\hline
\end{tabular}


Table 5 Summary of the results for low power design

\begin{tabular}{llllllll}
\hline & 1st test & 2nd test & 3rd test & Avg. & typical & Geo. mean & max \\
\hline Current consumption $[\mu A]$ & 21.97 & 20.39 & 20.39 & 20.92 & 6.42 & 17.0 & 45.06 \\
$\begin{array}{l}\text { Power consumption when used for } \\
\begin{array}{l}10 \text { years [mAh] } \\
\text { Life span of batteries [years] }\end{array}\end{array}$ & 1924.6 & 1780.9 & 1786.1 & 1830.5 & 562.4 & 1489.9 & 3947 \\
\hline
\end{tabular}

to allow electrical isolation without affecting the battery operation of the ultrasonic water meter at all.

\section{Declarations}

We have confirmed that there is no potential competing interests. All authors have verified the submitted manuscript and this paper has not been published in any other journals.

\section{Authors' contributions}

YSH conceptualized the idea, formulated a set of equations and prepared the manuscript. CHL designed and implemented a low-power ultrasonic water meter. Both authors are read and approved the final manuscript.

\section{Funding}

This article was invited from SWGIC 2018.

\section{Availability of data and materials}

All the data generated in this article are available and they can be shard for comparison.

\section{Competing interests}

The authors declare that they have no competing of interests.

Received: 28 May 2019 Accepted: 1 October 2019

Published online: 27 November 2019

\section{References}

ACAM Messelektromik gmbh, "TDC-GP30 System-Integrated Solution for Ultrasonic Flow Meters (DB_GP30_Vol1_en)", 2015, DB_GP30Y_Vol1_en V0.0, (www.acam.de)

Flowmeter classification and features, Korea Water Resources Corporation (in Korean), 2015

"http://www.evebattery.com/en2/products.aspx?category=40", Dec. 2015

"http://www.powerstream.com/battery-capacity-calculations.htm", Dec., 2015

Lee, C.-H., \& Hong, Y.-S. An ultrasonic water meter using differential time-of-flight flow measurement method, Domestic Patent (No.10-1622566), 2016

Lee C-H, Hong Y-S (2014) Low power design and implementation of portable temperature and humidity meter based on power consumption modeling. J Korean Acad Ind Sci Technol 15(2):1027-1035

Lee C-H, Hong Y-S (2015) A design and implementation of ultrasonic water meter using dToF. J Korea Inf Technol Soc 13(4): $17-26$

Lee C-H, Jeon H-K, Hong Y-S (2017) An implementation of ultrasonic water meter using dToF measurement. Cogent Engineering 4:1-22

Lee D-G et al (2009) Rate of under-registration and counterplan of flow water, Korea Water Resources Corporation, KWIGTRC-09-02, Research Report (in Korean), p 12

Maxim Integrated Products Inc., "MAX35101 Time-to-Digital Converter with Analog Front-End", https://www.maximintegrated. com/en/products/industries/metering-energy-measurement/MAX35101.html, 2015

Ministry of Industry and Commerce, Water meter technical standards No.2014-279, 2015

John Shen, "Ultrasonic Water Meter The Future for Residential Water Metering," 2015 www.SpireMT.com

Spitzer DW Editor(1990) "Flow Measurement Practical Guides for Measurement and Control", Instrument Society of America, pp 415-441

Texas Instruments, "TDC1000 ultrasonic sensing analog front end (AFE) data sheet", 2015, http://www.ti.com/product/tdc1 000?qgpn=tdc1000

\section{Publisher's Note}

Springer Nature remains neutral with regard to jurisdictional claims in published maps and institutional affiliations. 